\title{
Corrigendum
}

\section{Corrigendum to "Subdural Empyema Complicating Bacterial Meningitis: A Challenging Diagnosis in a Patient with Polysubstance Abuse"}

\author{
Melissa Dakkak, William Russell Cullinane Jr., and Virin Rajiv Neil Ramoutar \\ Department of Medicine, University of Florida, 653 W. 8th Street, Box L18, Jacksonville, FL 32209, USA \\ Correspondence should be addressed to Virin Rajiv Neil Ramoutar; virin.ramoutar@jax.ufl.edu \\ Received 10 September 2017; Accepted 3 October 2017; Published 14 November 2017 \\ Copyright ( 2017 Melissa Dakkak et al. This is an open access article distributed under the Creative Commons Attribution \\ License, which permits unrestricted use, distribution, and reproduction in any medium, provided the original work is properly \\ cited.
}

In the article titled "Subdural Empyema Complicating Bacterial Meningitis: A Challenging Diagnosis in a Patient with Polysubstance Abuse" [1], there was an error in the abstract section, where "pneumococcal pneumonia" should be corrected to "pneumococcal meningitis."

\section{References}

[1] M. Dakkak, W. R. Cullinane Jr., and V. R. N. Ramoutar, "Subdural empyema complicating bacterial meningitis: a challenging diagnosis in a patient with polysubstance abuse," Case Reports in Medicine, vol. 2015, Article ID 931819, 3 pages, 2015. 


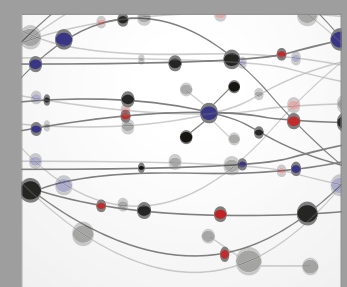

The Scientific World Journal
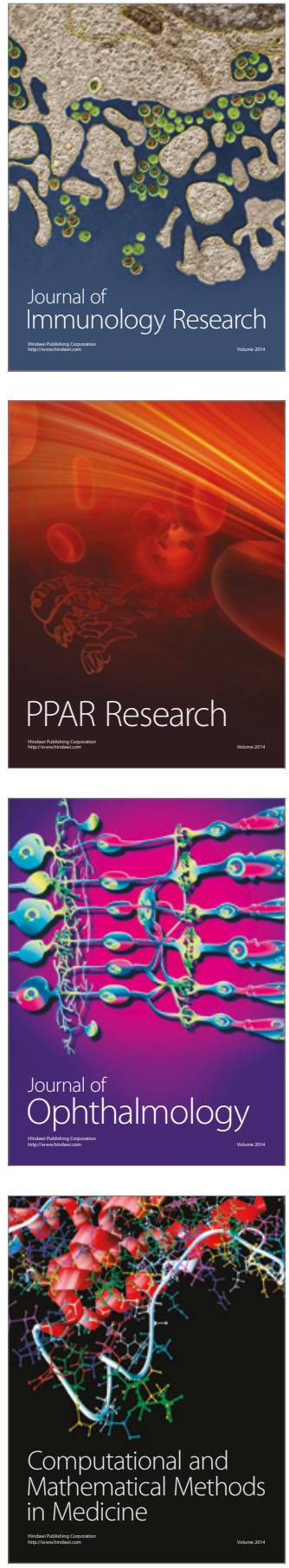

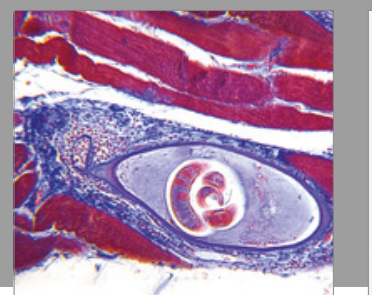

Gastroenterology Research and Practice
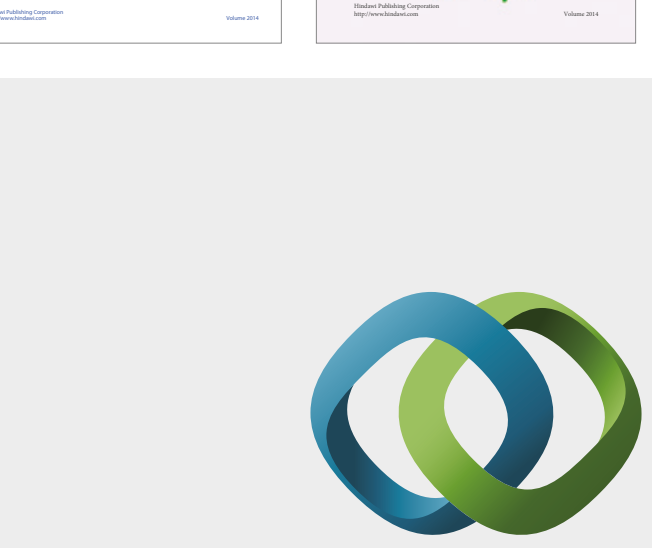

\section{Hindawi}

Submit your manuscripts at

https://www.hindawi.com
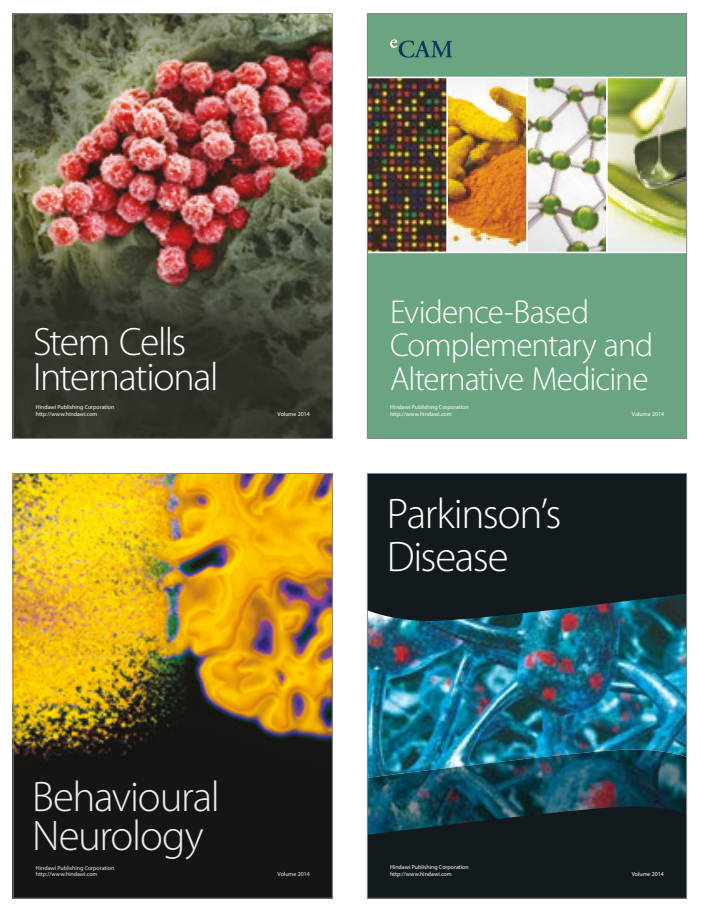
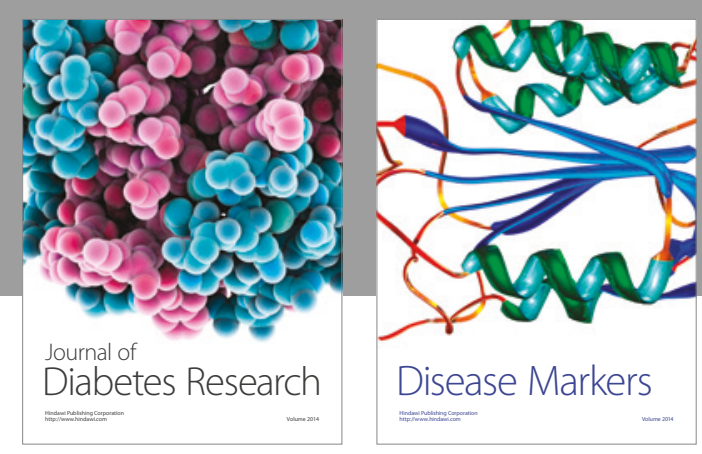

Disease Markers
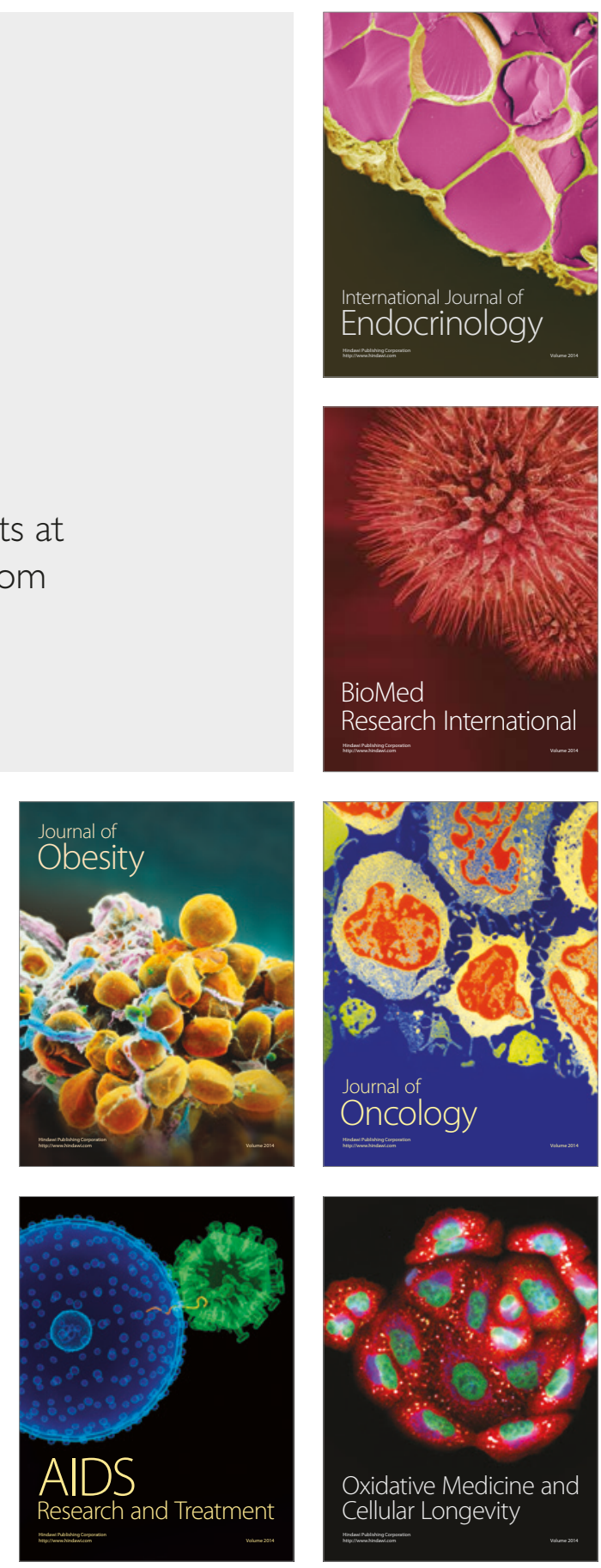